\title{
Commentary
}

Sir,

Spontaneous spinal epidural hematoma (SSEH) is a rare clinical disorder that might result in permanent neurological deficit and death when left untreated ${ }^{[1]}$ The usual clinical presentation of SSEH is sudden neck or back pain that progresses toward paraparesis or quadriparesis, depending on the level of the lesion. ${ }^{[1]}$ The etiology of SSEH includes undiagnosed, acquired, or congenital coagulopathies such as hemophilia, anticoagulant use, hypertension, neoplasm, arteriovenous malformation, trauma or postoperative complications, cough, vomiting, sneezing, or weight lifting that increases venous pressure. However, in $40 \%$ of patients with such hemorrhages, no etiology can be identified and they are classified as idiopathic SSEH. ${ }^{[2]}$

Up to date, there have been disputes about the origin of these hematomas. Most researchers conclude that SSEHs arise from the epidural venous plexus in the spinal epidural space because it lacks venous valves, and undulating pressure from the thoracic and abdominal cavities can impact it directly. ${ }^{[3]}$ It is believed that epidural venous pressure cannot be lower than the intrathecal pressure. If this happens, then the venous vessels can dilate and induce a mass effect; however, it is deemed impossible to take place. ${ }^{[3]}$ The arterial structures responsible for the hemorrhage in the epidural area are located in the posterior and posterolateral areas. ${ }^{[2,3]}$

The most common site of a SSEH is the cervicothoracic region or thoracolumbar region. ${ }^{[1]}$ Although the upper cervical segment is very mobile, it gives rise to the brachial plexus and due to the rigid structure of the thoracic spine, lower cervical spine mobility is limited. However, stretching in different directions raises the vascular vulnerability. ${ }^{[2-4]}$ Often, the hematoma is located posteriorly or posterolaterally, usually extending over 2-3 segments. The clinical presentation may vary depending on the size and location of the hematoma. ${ }^{[4]}$

In contrast to the literature, ventral SSEH is very rare. It is considered to be attached to the vertebral bodies of the dura membrane of the ventral surface of the spinal cord. But, an epidural hematoma may lead to dissection. The bleeding can occur from the blood vessels on the lateral side surface. ${ }^{[5]}$ It can pass into the anterior from posterolateral of spinal cord or it can occur from a traumatic vertebral body bleeding, or may be the bleeding caused due to the cervicothoracic junction may be replaced down by gravity. ${ }^{[6]}$

As a result when diagnosed with SSEH, it is a very rare neurosurgical emergency event. ${ }^{[7]}$ Therefore, if not diagnosed early, it may result in catastrophic result. There was my experience in separate three cases about SSEH. The cases were adult and they were located close to cervicothoracic junction and in posteriorly. Moreover, urgently, it was required to perform two or three level hemilaminectomy for these cases because of epidural solid clot. It was not easy to clean the totally epidural solid clot. That is why the ventral epidural clot may not be easily cleaned. For that reason, at least, adequate posterior decompression on spinal cord is required. ${ }^{[5]}$

Total laminectomy is not desirable for a child. However, it may be required due to both the very delicate cervical and thoracic spinal cords and to prevent the neurological deficits. ${ }^{[5]}$ Thereby, after adequate posterior decompression, remaining ventral blood clot is not a problem. The remaining blood clots as soon as will be spontaneously absorbed. ${ }^{[6]}$ As in this case report, only laminectomy may be insufficient. (It was understood from radiological imaging such as hemilaminectomy or partial facetectomy.) But if it is not a solid blood clot, it may be enough to be drained with facetectomy.

However, need to make prepare for everything, especially in a 14-year-old patient, total laminectomy should be done through the blood column necessary to prevent remaining neurologic deficits. ${ }^{[5]}$ Moreover, instead of total laminectomy, laminoplasty was preferable to protect the spinal stability. For this, only one side of the lamina-free edge can be connected back to the vertebral bone, and it does not compress the spinal cord. ${ }^{[5]}$ Further, hemostasis in pediatric patients requires utmost care. Fibrin derivatives (such as Fluosil ${ }^{\circledR}$ ) can be used prior to surgical closure. Washing with serum saline can be done in severe venous bleeding. In addition, drugs such as intravenous tranexamic acid (Transamine ${ }^{\circledR}$ ) may be administered to prevent blood loss for children. ${ }^{[8]}$

Finally, the interval between the onset of SSEH symptoms and the surgical decompression determines the SSEH prognosis. ${ }^{[9]}$ This interval is related to the degree of preoperative neurologic deficits. According to the literature, incomplete spinal cord dysfunction takes place 
within the first $48 \mathrm{~h}$. If another $36 \mathrm{~h}$ has passed, complete spinal cord dysfunction occurs. ${ }^{[9]}$ The successful neurologic prognosis seems to be associated with the early application of decompressive surgery consistent with the literature. ${ }^{[5,9]}$

\section{Vaner Köksal}

Department of Neurosurgery, Medical School, Recep Tayip Erdoğan University, Rize, Turkey

Address for correspondence:

Dr. Vaner Köksal, Department of Neurosurgery, Medical School, Recep Tayip Erdoğan University, Rize, Turkey. E-mail: vanerkoksal@hotmail.com

\section{References}

1. Baek BS, Hur JW, Kwon KY, Lee HK. Spontaneous spinal epidural hematoma. J Korean Neurosurg Soc 2008;44:40-2.

2. Ofluoglu E, Ozdemir A, Toplamaoglu H, Sofuoglu E. Spontaneous cervical epidural hematoma causing Brown-Sequard syndrome: Case report. Turk Neurosurg 2009;19:99-102.

3. Riaz S, Jiang H, Fox R, Lavoie M, Mahood JK. Spontaneous spinal epidural hematoma causing Brown-Sequard syndrome: Case report and review of the literature. J Emerg Med 2007;33:241-4.

4. Kreppel D, Antoniadis G, Seeling W. Spinal hematoma: A literature survey with meta-analysis of 613 patients. Neurosurg Rev 2003;26:1-49.
5. Kim T, Lee CH, Hyun SJ, Yoon SH, Kim KJ, Kim HJ. Clinical outcomes of spontaneous spinal epidural hematoma: A comparative study between conservative and surgical treatment. J Korean Neurosurg Soc 2012;52:523-7.

6. Köksal V, Özdemir B. A calvarial acute subdural hematoma migrating into the spinal canal in a young male. Am J Emerg Med 2015;33:1537.e1-4.

7. Ratre S, Yadav Y, Choudhary S, Parihar V. Spontaneous ventral spinal epidural hematoma in a child - A case report and review of literature. J Neurosci Rural Pract 2016;7:297-9.

8. Guay J, de Moerloose P, Lasne D. Minimizing perioperative blood loss and transfusions in children. Can J Anaesth 2006;53 6 Suppl: S59-67.

9. Liu Z, Jiao Q, Xu J, Wang X, Li S, You C. Spontaneous spinal epidural hematoma: Analysis of 23 cases. Surg Neurol 2008;69:253-60.

This is an open access article distributed under the terms of the Creative Commons Attribution-NonCommercial-ShareAlike 3.0 License, which allows others to remix, tweak, and build upon the work non-commercially, as long as the author is credited and the new creations are licensed under the identical terms.

\begin{tabular}{|l|l|}
\hline \multicolumn{2}{|c|}{ Access this article online } \\
\hline Quick Response Code: & Website: \\
\hline & www.ruralneuropractice.com \\
\cline { 2 - 3 } & \\
\hline & \\
\hline
\end{tabular}

How to cite this article: Köksal V. Commentary. J Neurosci Rural Pract 2016;7:300-1. 